Open Access

\title{
Intravenous hydrogen sulfide does not induce neuroprotection after aortic balloon occlusion-induced spinal cord ischemia/ reperfusion injury in a human-like porcine model of ubiquitous arteriosclerosis
}

Andre Bredthauer ${ }^{1,2^{*}}$ (D) Karla Lehle ${ }^{3}$, Angelika Scheuerle ${ }^{4}$, Hubert Schelzig ${ }^{5}$, Oscar McCook ${ }^{2}$, Peter Radermacher ${ }^{2}$, Csaba Szabo ${ }^{6}$, Martin Wepler ${ }^{2}$ and Florian Simon ${ }^{2,5}$

\footnotetext{
* Correspondence: andre. bredthauer@ukr.de

'Department of Anesthesiology, University Hospital Regensburg, Franz-Josef-Strauß-Allee 11, 93053 Regensburg, Germany ${ }^{2}$ Institute of Anesthesiological Pathophysiology and Process Engineering, University Hospital Ulm, Helmholtzstraße 8/1, 89081 Ulm, Germany

Full list of author information is available at the end of the article
}

\begin{abstract}
Objective: In rodents, intravenous sulfide protected against spinal cord ischemia/ reperfusion (I/R) injury during aortic balloon occlusion. We investigated the effect of intravenous sulfide on aortic occlusion-induced porcine spinal cord I/R injury.

Methods: Anesthetized and mechanically ventilated "familial hypercholesterolemia Bretoncelles Meishan" (FBM) pigs with high-fat-diet-induced hypercholesterolemia and atherosclerosis were randomized to receive either intravenous sodium sulfide $2 \mathrm{~h}$ (initial bolus, $0.2 \mathrm{mg} \mathrm{kg}$ body weight (bw) ${ }^{-1}$; infusion, $2 \mathrm{mg} \mathrm{kg} \mathrm{bw}^{-1} \mathrm{~h}^{-1} ; n=4$ ) or vehicle (sodium chloride, $n=4$ ) prior to $45 \mathrm{~min}$ of thoracic aortic balloon occlusion and for $8 \mathrm{~h}$ during reperfusion (infusion, $1 \mathrm{mg} \mathrm{kg} \mathrm{bw^{-1 }} \mathrm{h}^{-1}$ ). During reperfusion, noradrenaline was titrated to maintain blood pressure at above $80 \%$ of the baseline level. Spinal cord function was assessed by motor evoked potentials (MEPs) and lower limb reflexes using a modified Tarlov score. Spinal cord tissue damage was evaluated in tissue collected at the end of experiment using hematoxylin and eosin and Nissl staining.
\end{abstract}

Results: A balloon occlusion time of 45 min resulted in marked ischemic neuron damage (mean of 16\% damaged motoneurons in the anterior horn of all thoracic motor neurons) in the spinal cord. In the vehicle group, only one animal recovered partial neuronal function with regain of MEPs and link motions at each time point after deflating. All other animals completely lost neuronal functions. The intravenous application of sodium sulfide did not prevent neuronal cell injury and did not confer to functional recovery.

Conclusion: In a porcine model of I/R injury of the spinal cord, treatment with intravenous sodium sulfide had no protective effect in animals with a pre-existing arteriosclerosis.

Keywords: Hydrogen sulfide, I/R injury, Ubiquitous arteriosclerosis, Aortic aneurysm, Neuro protection 


\section{Background}

During open aortic surgery, interrupting blood flow through the aorta by applying a cross-clamp is often a key step to allow for surgical repair. Consequently, ischemia is induced in parts of the body distal to the clamp site. This significant alteration in blood flow by cross-clamping induces hemodynamic changes. Upon release of the cross-clamp, the blood flow is restored, triggering an ischemia/reperfusion (I/R) injury, leading to tissue inflammation, humoral changes, and lactate acidosis that increases the risk of multi-organ failure (MOF) and therefore affects postoperative outcome [1]. The most vulnerable organs are the kidney (renal failure, incidence 4.6-5.6\%) and the spinal cord (ischemia, incidence 2.7-13.2\%) [2, 3].

Hydrogen sulfide $\left(\mathrm{H}_{2} \mathrm{~S}\right)$ is an endogenously produced gaseous transmitter and neuromodulator, derived from L-cysteine in several organs, such as the brain, heart, kidney, and liver [4]. $\mathrm{H}_{2} \mathrm{~S}$ plays many important roles in the central nervous system under physiological and pathological states, especially in secondary neuronal injury. $\mathrm{H}_{2} \mathrm{~S}$ has been shown to protect the brain from $I / R$ injury via maintenance of mitochondrial function, inhibiting pro-inflammatory factors, neutralizing reactive oxygen species (ROS), and reducing apoptosis [5]. In a rat model of aortic balloon occlusion for $12 \mathrm{~h}$, pre-emptive intraperitoneal injection of $30 \mu \mathrm{mol} \mathrm{kg}{ }^{-1}$ sodium hydrogen sulfide (NaSH) reduced spinal cord infarct area and improved hind motor function $48 \mathrm{~h}$ after aortic occlusion [6]. In this study, it was reported that the reduced spinal cord injury was due to enhanced neurocyte autophagy. As of today, no data on the effects of $\mathrm{H}_{2} \mathrm{~S}$ on spinal cord injury after aortic clamping in large animals is available. The transferability of the efficacy of $\mathrm{H}_{2} \mathrm{~S}$-based therapies from rodent models into larger animals may be questioned, at least in part due to their large surface area/mass ratio [7-10]. Therefore, the aim of this study was to test the hypothesis whether an intravenous (i.v.) formulation of sodium sulfide $\left(\mathrm{Na}_{2} \mathrm{~S}\right)$ would induce neuroprotective effects during porcine aortic balloon occlusion-induced spinal cord I/R injury using a human-like porcine model of ubiquitous arteriosclerosis.

\section{Materials and methods}

\section{Animals}

The experiments were performed in adherence with the National Institutes of Health Guidelines on the use of Laboratory Animals and after approval of the protocol by the regional council of Tübingen (Registration number 905). Eight downsized familial hypercholesterolemia Bretoncelles Meishan (FBM) pigs of either sex with a mean bodyweight of $64 \mathrm{~kg}$ (range 24-92 kg) were used. The pigs were housed and fed as described previously $[11,12]$. $\mathrm{Na}_{2} \mathrm{~S}$ for i.v. injection was kindly provided by Csaba Szabo (Department of Anesthesiology, University of Texas Medical Branch, Galveston, TX, USA) and synthetized using $\mathrm{H}_{2} \mathrm{~S}$ gas as the starting material, which was bubbled through an aqueous solution of sodium hydroxide $(\mathrm{NaOH})$ and saline, formulated to $\mathrm{pH}$ neutrality and iso-osmolarity. This solution was filtered and placed under $\mathrm{N}_{2}$ atmosphere [13-15].

\section{Procedure}

The anesthetic procedure, surgical preparation, placement of catheters, and physiological measurements have been described in detail previously $[12,16]$. Briefly, after 
induction of anesthesia (i.v., propofol, ketamine) and subsequent endotracheal intubation, anesthesia was maintained with continuous i.v. propofol $\left(6-8 \mathrm{mg} \mathrm{kg}^{-1} \mathrm{~h}^{-1}\right)$ and remifentanil $\left(15-20 \mu \mathrm{g} \mathrm{kg}{ }^{-1} \mathrm{~h}^{-1}\right)$. Pigs were mechanically ventilated $\left[\mathrm{FiO}_{2} 0.25-0.35\right.$, adjusted to keep arterial $\mathrm{pO}_{2}$ levels $>100 \mathrm{mmHg}$, tidal volume $10 \mathrm{~mL} \mathrm{~kg}$, positive end-expiratory pressure (PEEP) $5 \mathrm{cmH}_{2} \mathrm{O}$, inspiratory/expiratory time ratio 1:1.5, respiratory rate $10-13 \mathrm{~min}^{-1}$ adjusted to maintain arterial $\mathrm{pCO}_{2}$ between 35 and $40 \mathrm{mmHg}]$. These ventilator settings were used because swine are particularly susceptible to atelectasis formation in dependent lung regions due to the lack of alveolar collateral ventilation [16]. Sodium heparin $\left(200 \mathrm{IU} \mathrm{h}^{-1}\right)$ was continuously infused for anticoagulation. Via surgical cut-downs, the catheters were placed in the A. carotis dextra for measurement of blood pressure in the upper half of the body (mean arterial pressure, MAP proximal), trans-pulmonary single indicator thermodilution-cardiac index (CI), and the intra-thoracic blood volume index (ITBVI), a well-accepted marker of cardiac preload [17], as well as in the V. jugularis dextra for measurement of central venous pressure (CVP) and drug infusion. Via femoral cut-down, catheter sheaths were introduced into the Aa. femorales sinistra and dextra for distal blood pressure recording (MAP distal) and placement of inflatable balloon catheters. Adapting a technique previously published by several authors $[18,19]$, one catheter was placed directly above the aortic trifurcation, and the other one directly downstream of the A. subclavia sinistra, the correct position of which was manually controlled via a left-sided thoracotomy. This approach was chosen to prevent any perfusion of the spinal cord via collateral flow distal to the proximal balloon [20], which could result from variable bifurcation of the A. radicularis magna anterior [21]. The intra-aortic balloon occlusion was used to avoid mechanical injury related to clamp placement and release per se [22]. After 30 to 45 min of occlusion time, the balloon catheters were deflated. We started with an occlusion time of $30 \mathrm{~min}$, followed by $40 \mathrm{~min}$ in preliminary experiments to test the response of this pig strain to a spinal cord I/R injury. Aortic occlusion was then performed for $45 \mathrm{~min}$ because this ischemia time had resulted in moderate neuronal damage (5 to $15 \%$ of all motor neurons) in the spinal cord in previous experiments [23]. In addition, $45 \mathrm{~min}$ of aortic occlusion prevented both the large spinal cord infarction over several segments reported in pigs after a clamping period of $60 \mathrm{~min}$ or longer [24] and the fairly mild tissue damage observed after only $30 \mathrm{~min}$ of clamping [25, 26]. Pigs were normothermic at the beginning of preparation period, and body temperature dropped to $32{ }^{\circ} \mathrm{C}$ at the start of either sodium sulfide or sodium chloride infusion. Pigs of this particular strain are known to spontaneously develop hypothermia during anesthesia [12]. Hemodynamic data, motor evoked potentials (MEPs), and neuronal function were assessed during aortic balloon occlusion and at $1 \mathrm{~h}, 4 \mathrm{~h}$, and $8 \mathrm{~h}$ of reperfusion.

\section{Application of sodium sulfide $\left(\mathrm{Na}_{2} \mathrm{~S}\right)$}

Two hours before balloon occlusion, animals were treated with saline (vehicle group) or sodium sulfide (study group). The sodium sulfide infusion rate (initial bolus $0.2 \mathrm{mg} \mathrm{kg}^{-1}$ followed by continuous i.v. infusion of $2 \mathrm{mg} \mathrm{kg}^{-1} \mathrm{~h}^{-1}$ during the $2 \mathrm{~h}$ before aortic occlusion, and $1 \mathrm{mg} \mathrm{kg}^{-1} \mathrm{~h}^{-1}$ during the $8 \mathrm{~h}$ reperfusion) was based on previous studies [27]. During balloon occlusion time, sodium sulfide or vehicle infusion was stopped. 


\section{Harvesting, measurements, and calculations}

The animals were euthanized in deep anesthesia by giving a bolus of phenobarbital (Narkodorm Alvetra, Neumünster, Germany) and i.v. potassium chloride $(20 \mathrm{mmol}$, Braun, Melsungen, Germany). Tissue samples of the lumbar and thoracic spinal cord were isolated immediately post mortem and fixed in $6 \%$ buffered paraformaldehyde, and standard 3- $\mu \mathrm{m}$ paraffin sections were stained with hematoxylin and eosin (HE). Particular attention was paid on the anterior horn $(\mathrm{AH})$, because of the vulnerability due to a hypoxic damage [28]. In addition, spinal cord sections were analyzed after nuclear cresol violet staining (Nissl staining) for neuronal damage [26].

Spinal cord function was evaluated by MEPs as described previously [24, 29, $29,30]$. Three electrodes were inserted into the scalp, and one into the soft palate to apply electric impulses (Digitimer Ltd., MultiPulse Stimulator D185 mark IIa) to the motor cortex. To quantify MEPs, electrodes were inserted in the muscles of the limbs to measure neuronal potential (ExcelTech Ltd., ExlTek Neuro$\max 1004)$. After electric stimulation of the cerebral motor cortex, the neural responses of the upper and the lower limbs were recorded. Decrease of more than $75 \%$ of the MEP amplitude was accepted as an indication of ischemic spinal cord dysfunction [24, 29]. MEP signal disappeared within $5 \mathrm{~min}$ in all animals as a sign of sufficient aortic occlusion. MEPs were triggered directly before aortic occlusion as well as $1 \mathrm{~h}, 2 \mathrm{~h}, 4 \mathrm{~h}$, and $8 \mathrm{~h}$ after reperfusion.

In addition, spinal cord function was clinically evaluated by observing the movements of the upper and lower limbs in response to claw clamping during temporarily reduced anesthesia. The muscular response was classified as follows: $0=$ no movement, $1=$ muscular movement, 2 = joint movement, 3 = normal movement; an additional score of 4 was attributed if spontaneous movement was present even without stimulation by claw clamping. The reaction was measured before clamping (measuring point, MP1) and $1 \mathrm{~h}$ (MP2), $2 \mathrm{~h}$ (MP3), $4 \mathrm{~h}$ (MP4), and $8 \mathrm{~h}$ (MP5) after reperfusion. The reaction of the upper extremities was used to demonstrate the normal response.

Heart rate, MAP proximal, MAP distal, CVP, ITBVI, and CI were recorded as hemodynamic parameters. Arterial blood samples were collected to analyze blood gases, acid-base status, electrolytes, hemoglobin content, $\mathrm{O}_{2}$ saturation, and glucose levels.

\section{Statistical analysis}

All data are presented as median (interquartile range, IQR). A Mann-Whitney $U$ test was performed for systemic hemodynamics, gas exchange, acid-base status, and histology. A $p$ value of less than 0.05 was considered statistically significant. IBM SPSS Statistics software (Version 24.0.0.0) was used for statistical evaluation and graphical display.

\section{Results}

Mortality rates

All animals survived the experiments until the end of the observation period (reperfusion time, $8 \mathrm{~h}$ ). 


\section{Hemodynamics, gas exchange, acid-base status}

Table 1 presents data on systemic hemodynamics, gas exchange, acid-base status, and electrolytes. There were no statistically significant differences between the two groups.

\section{Histology}

Animals from all groups showed the physiological structure of the spinal cord. I/R injury caused accumulations of single reactive, predominantly mononuclear round cell/ glial infiltrates, atherosclerotic alterations in arterioles/arteries, and slight swelling of the perikaryon of neurons in the anterior horn of the spinal cord (Fig. 1) of all animals. Two pigs from the vehicle group developed an infarct at both levels of the spinal cord. The cross sections presented edema, eosinophilic necrosis of ganglion cells, and motor neurons. The other animals of this group were without other pathological findings. One pig of the sulfide group showed an acute infarct with hypoxic necrosis of ganglion cells, endothelial cell damage, and edema in the lumbar and thoracic spinal cord. The remaining three animals from the sodium sulfide group were without other pathological findings.

In preliminary experiments, it was shown that an increase in the clamping time resulted in an increase in the neuronal damage (data not shown). A clamping time of 45 min caused a damage of neurons in the thoracic and lumbar spinal cord (mean proportion of damaged neurons, $16.4 \%$ and $16.2 \%$, respectively). Treatment with sodium sulfide did not reduce the damage of neurons. The mean percentage of damaged neurons in the anterior horn of the thoracic and lumbar spinal cord was $21.1 \%$ and $23.9 \%$, respectively. The slight increase in the sodium sulfide group might be a result of the animal with the large active infarction (see above). There was no significant difference between the vehicle and the sodium sulfide group. Typical histological examples are demonstrated in Figs. 2 and 3.

\section{Motor evoked potentials (MEPs)}

MEPs of the spinal cord were used to measure the extent of the damage of the spinal cord after ischemic damage. In the study groups, two animals of the vehicle group and one animal of the sodium sulfide group showed small but measurable MEPs at 2 and $4 \mathrm{~h}$ after balloon deflating. The function also got lost after $8 \mathrm{~h}$ of reperfusion.

\section{Neurologic function}

The clinical evaluation of the neurological function was evaluated at different time points. The reference at the upper extremities was always 7 points ( 3 points for normal reaction to claw clamping and 4 additional points for spontaneous movements). Furthermore, each animal showed maximal reflexes of the hind legs before balloon occlusion. In the sodium chloride group, only one animal showed link motions (2 points) at each time point during reperfusion. All other animals in both groups lost muscular reaction.

\section{Discussion}

The present study tested the hypothesis if a (pre-)treatment with sodium sulfide $\left(\mathrm{Na}_{2} \mathrm{~S}\right)$ would reduce neuronal damage in a clinically relevant porcine model of thoracic aortic 
Table 1 Systemic hemodynamic, gas exchange, and acid-base status

\begin{tabular}{|c|c|c|c|}
\hline Parameter & Group & $\mathrm{NaCl}$ & $\mathrm{Na}_{2} \mathrm{~S}$ \\
\hline \multirow[t]{3}{*}{ Core temp. $\left({ }^{\circ} \mathrm{C}\right)$} & Baseline & $32(31.8-32.1)$ & $31.8(31.5-32.0)$ \\
\hline & $4 \mathrm{~h}$ reperfusion & $32(31.8-32.0)$ & $32.0(31.9-32.1)$ \\
\hline & $8 \mathrm{~h}$ reperfusion & $32(31.8-32.1)$ & $32.0(32.0-32.0)$ \\
\hline \multirow[t]{3}{*}{ Hemoglobin $\left(g \mathrm{~L}^{-1}\right)$} & Baseline & $83(71-88)$ & $82(74-94)$ \\
\hline & $4 \mathrm{~h}$ reperfusion & $101(92-108)$ & $101(81-123)$ \\
\hline & $8 \mathrm{~h}$ reperfusion & $98(83-107)$ & $102(82-132)$ \\
\hline \multirow[t]{3}{*}{ Heart rate (bpm) } & Baseline & $72(62-81)$ & 74 (54-94) \\
\hline & $4 \mathrm{~h}$ reperfusion & $89(47-109)$ & $112(89-135)$ \\
\hline & $8 \mathrm{~h}$ reperfusion & $82(49-109)$ & $106(78-130)$ \\
\hline \multirow[t]{3}{*}{ CVP $(\mathrm{mmHg})$} & Baseline & $8(5-10)$ & $7(4-10)$ \\
\hline & $4 \mathrm{~h}$ reperfusion & $9(7-10)$ & $7(5-9)$ \\
\hline & $8 \mathrm{~h}$ reperfusion & $8(7-10)$ & $7(4-9)$ \\
\hline \multirow[t]{3}{*}{$\mathrm{Cl}\left(\mathrm{ml} \mathrm{kg}{ }^{-1} \mathrm{~min}^{-1}\right)$} & Baseline & $84.4(64.2-102.8)$ & $72.5(61.9-78.3)$ \\
\hline & $4 \mathrm{~h}$ reperfusion & $85.1(48.6-125)$ & $90.7(70.3-121)$ \\
\hline & $8 \mathrm{~h}$ reperfusion & $80.0(48.8-108.3)$ & $83.7(54.5-120)$ \\
\hline \multirow[t]{3}{*}{ MAP $(\mathrm{mmHg})$} & Baseline & $82(63-93)$ & $77(70-86)$ \\
\hline & $4 \mathrm{~h}$ reperfusion & $82(78-91)$ & $84(59-107)$ \\
\hline & $8 \mathrm{~h}$ reperfusion & $84(78-88)$ & $81(69-95)$ \\
\hline \multirow[t]{3}{*}{ ITBVI (mL m²) } & Baseline & 636 (537-786) & $629(482-762)$ \\
\hline & $4 \mathrm{~h}$ reperfusion & 727 (509-1173) & $612(496-805)$ \\
\hline & $8 \mathrm{~h}$ reperfusion & 665 (587-780) & $577(509-742)$ \\
\hline \multirow[t]{3}{*}{ Arterial $\mathrm{pO}_{2}(\mathrm{mmHg})$} & Baseline & $168(147-189)$ & $151(134-161)$ \\
\hline & $4 \mathrm{~h}$ reperfusion & $169(136-187)$ & $126(92-150)$ \\
\hline & $8 \mathrm{~h}$ reperfusion & $171(145-187)$ & $120(91-138)$ \\
\hline \multirow[t]{3}{*}{ Arterial $\mathrm{pCO}_{2}(\mathrm{mmHg})$} & Baseline & $39(37-39)$ & $38(35-43)$ \\
\hline & $4 \mathrm{~h}$ reperfusion & $36(33-38)$ & $42(35-47)$ \\
\hline & $8 \mathrm{~h}$ reperfusion & $39(36-41)$ & $42(39-48)$ \\
\hline \multirow[t]{3}{*}{ Horowitz index (mmHg) } & Baseline & $584(490-630)$ & $604(536-640)$ \\
\hline & $4 \mathrm{~h}$ reperfusion & $562(543-623)$ & $505(368-600)$ \\
\hline & $8 \mathrm{~h}$ reperfusion & $569(483-623)$ & $483(364-552)$ \\
\hline \multirow[t]{3}{*}{ Arterial pH } & Baseline & $7.48(7.42-7.56)$ & $7.52(7.46-7.56)$ \\
\hline & $4 \mathrm{~h}$ reperfusion & $7.43(7.36-7.50)$ & 7.37 (7.29-7.49) \\
\hline & $8 \mathrm{~h}$ reperfusion & $7.41(7.34-7.50)$ & $7.32(7.10-7.44)$ \\
\hline \multirow[t]{3}{*}{ Arterial base excess $\left(\mathrm{mmol} \mathrm{L}^{-1}\right)$} & Baseline & $5.2(0.8-10.8)$ & $7.9(3,2-11.5)$ \\
\hline & $4 \mathrm{~h}$ reperfusion & $0,1(-4.6-3.6)$ & $1.2(-4-3.2)$ \\
\hline & $8 \mathrm{~h}$ reperfusion & $0.1(-3.8-4.5)$ & $-4,3(-15.3-2.4)$ \\
\hline \multirow[t]{3}{*}{$\mathrm{Na}^{+}\left(\mathrm{mmol} \mathrm{L}{ }^{-1}\right)$} & Baseline & $138(133-141)$ & $138(137-139)$ \\
\hline & $4 \mathrm{~h}$ reperfusion & $141(139-143)$ & $142(139-142)$ \\
\hline & $8 \mathrm{~h}$ reperfusion & $142(141-143)$ & $139(129-144)$ \\
\hline \multirow[t]{3}{*}{$\mathrm{K}^{+}\left(\mathrm{mmol} \mathrm{L} \mathrm{L}^{-1}\right)$} & Baseline & $3.4(3.1-3.7)$ & $3.8(3.6-4.2)$ \\
\hline & $4 \mathrm{~h}$ reperfusion & $3.9(3.8-4.1)$ & $4.1(3.8-4.7)$ \\
\hline & $8 \mathrm{~h}$ reperfusion & $3.9(3.9-4.0)$ & $3.9(3.4-4.5)$ \\
\hline \multirow[t]{3}{*}{ Glucose $\left(\mathrm{mg} \mathrm{dL}^{-1}\right)$} & Baseline & $114(105-136)$ & $144(103-172)$ \\
\hline & $4 \mathrm{~h}$ reperfusion & $169(155-202)$ & $185(126-239)$ \\
\hline & $8 \mathrm{~h}$ reperfusion & $159(88-222)$ & $160(124-235)$ \\
\hline
\end{tabular}

All data are median (range); sodium chloride (vehicle, $\mathrm{NaCl} n=4$ and sodium sulfide $\left(\mathrm{Na}_{2} \mathrm{~S}\right) n=4$. $h$ hours, CVP central venous pressure, $C l$ cardiac index, ITBV intra-thoracic blood volume index, MAP mean arterial pressure 


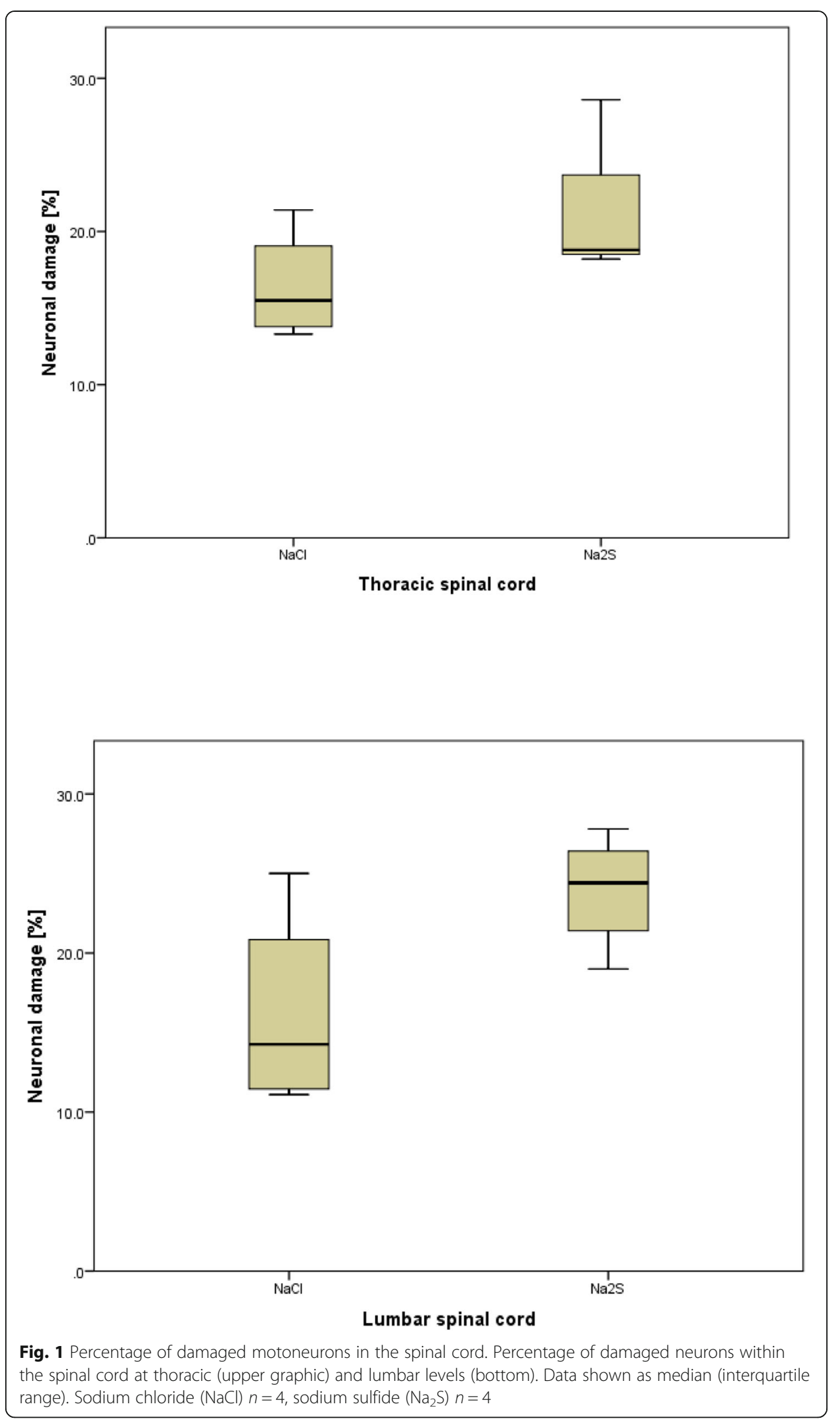



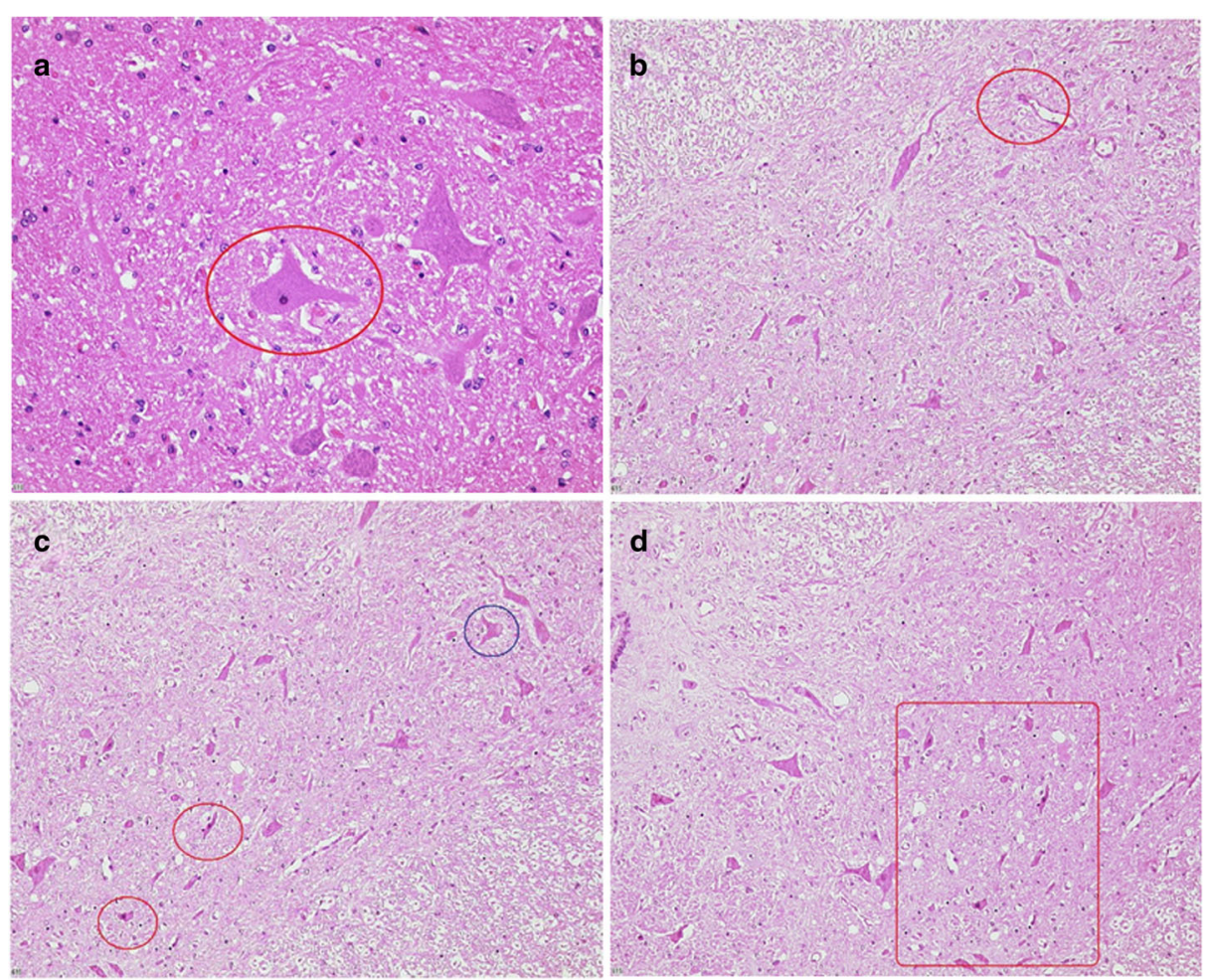

Fig. 2 Histology of the spinal cord of familial hypercholesterolemia Bretoncelles Meishan (FMB) pig. a Red frame marks swollen motor neuron with pyknotic nucleus indicating neuronal damage. b Red frames mark endothelial damage. $\mathbf{c}$ Red frames mark ischemic neurons with eosinophilic cytoplasm and darkened, shrunken nuclei. Blue frames indicate the formation of a vacuole within a neuron. $\mathbf{d}$ Red frames indicate hypoxic damage with eosinophilic gangliocyte necrosis

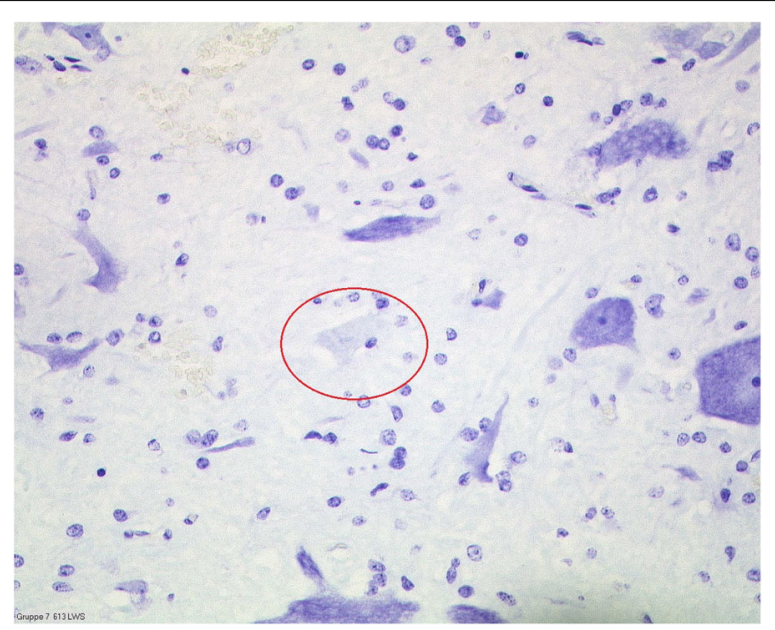

Fig. 3 Histology of the spinal cord of familial hypercholesterolemia Bretoncelles Meishan (FMB) pig. Niss staining of an ischemic infarction in the gray matter of an FBM pig on atherogenic diet after I/R injury. The red frame marks a necrotic neuron 
balloon occlusion-induced spinal cord I/R injury. However, treatment with intravenous $\mathrm{Na}_{2} \mathrm{~S}$ had no protective effect on I/R injury of the spinal cord.

In this study, swine were investigated because of their striking anatomical and physiological similarity to humans [31]. Furthermore, most studies focusing on pathophysiology utilize young animals, without any cardiovascular disease background, even though these animals are clearly not reflective of the pathophysiology of our patient population. However, the existence of atherosclerotic plaques in the vasculature represents an important independent risk factor for abdominal aortic aneurysms [32]. Therefore, we used a recently described porcine model of ubiquitous human-like atherosclerosis that is closer to the clinical situation for the therapy of aortic aneurysm $[11,12]$. These FBM pigs are a cross-bread of Rapacz farm pigs with smaller Chinese Meishan and French Bretoncelles strains. They are homologous for the R84 low-density lipoprotein (LDL) receptor mutation and feature human-like thin-cap fibroatheromas (TCFA) at a young age after an atherogenic diet as previously described $[11,12]$. They also have altered gene expression, like a downregulated erythropoietin receptor (EPO-R) expression, a lower systemic endothelial NO (eNO) production, but higher renal eNO levels when compared to other pig strains [12]. The downregulated EPO-R may be related to inflammation and oxidative stress and is a putative mechanism of EPO resistance in patients with heart and kidney failure [33, 34]. These circumstances might have contributed to the result that there was no attenuation of the I/R injury during $\mathrm{Na}_{2} \mathrm{~S}$ infusion, especially since multiple studies have noted that the therapeutic effect of $\mathrm{H}_{2} \mathrm{~S}$ donation requires the presence of an intact eNO synthase system [35-38].

The duration of aortic occlusion was based on previous experiments and the clinical situation of thoracic aortic cross-clamping in open surgical repair. In a pig model, this ischemia had resulted in neuronal injury (5-15\% of all motor neurons) in the spinal cord at $4 \mathrm{~h}$ of reperfusion [23]. In addition, $45 \mathrm{~min}$ of aortic occlusion prevented both the large spinal cord infarction over several segments reported in pigs after a clamping period of 60 min or longer [24] and the fairly mild tissue damage observed after only 30 min of clamping [26]. In our pigs with a pre-existing ubiquitous atherosclerosis, $45 \mathrm{~min}$ of ischemia and $8 \mathrm{~h}$ of reperfusion had resulted in the same extent of neuronal damage. Furthermore, half of the non-treated animals developed an infarct at both levels of the spinal cord and only one animal recovered partial neuronal function with regain of MEPs (Table 2) and link motions (Table 3) at each time point after reperfusion. The restriction in regaining neuronal function was also observed in a previous study using a pig model with the same balloon occlusion time [30].

Table 2 Motor evoked potentials (MEPs) during the experiment

\begin{tabular}{llllll}
\hline Group & MP1 & MP2 & MP3 & MP4 & MP5 \\
\hline Occlusion 30 min & $2108(100)$ & $384(18.2)$ & $1351(64.1)$ & $656(31.1)$ & $495(23.5)$ \\
Occlusion 40 min & $841(100)$ & $0(0)$ & $0(0)$ & $0(0)$ & $74(8.8)$ \\
$\mathrm{NaCl}$ (45 min) & $2245(100)$ & $144(6.4)$ & $318(14.2)$ & $267(11.9)$ & $64(2.9)$ \\
$\mathrm{Na}_{2} \mathrm{~S}(45 \mathrm{~min})$ & $1148(100)$ & $23(2)$ & $25(2.2)$ & $10(0.9)$ & $6(0.5)$ \\
\hline
\end{tabular}

All data are mean in microvolt and percentage of residual MEP compared to baseline (in brackets). Sodium chloride $(\mathrm{NaCl}), n=4$. Sodium sulfide $\left(\mathrm{Na}_{2} \mathrm{~S}\right) n=4$. The data of the two groups with $30 \mathrm{~min}(n=3)$ and $40 \mathrm{~min}(n=2)$ occlusion time were obtained in preliminary experiments as described above. MP measuring point 
Table 3 Clinical evaluation of hind motor function during the experiment. MP measuring point

\begin{tabular}{|c|c|c|c|c|c|}
\hline Group & MP1 & MP2 & MP3 & MP4 & MP5 \\
\hline $\begin{array}{l}\text { Occlusion } \\
30 \text { min }\end{array}$ & $\begin{array}{l}3+4(2 \times[3+4]+ \\
1 \times 3)\end{array}$ & $\begin{array}{l}1(1 \times 1+ \\
1 \times 2)\end{array}$ & $\begin{array}{l}2(1 \times 2+1 \times 1+ \\
1 \times 0)\end{array}$ & $\begin{array}{l}3+4(1 \times[3+4]+ \\
2 \times 0)\end{array}$ & $\begin{array}{l}3+4(1 \times[3+4]+1 \times 1 \\
+1 \times 0)\end{array}$ \\
\hline $\begin{array}{l}\text { Occlusion } \\
40 \text { min }\end{array}$ & $3+4(2 \times[3+4])$ & $0(2 \times 0)$ & $0(2 \times 0)$ & $3(1 \times 3+1 \times 0)$ & $2(1 \times 2+1 \times 0)$ \\
\hline $\begin{array}{l}\mathrm{NaCl} \\
(45 \mathrm{~min})\end{array}$ & $3+4(4 \times[3+4])$ & $\begin{array}{l}2(3 \times 0+ \\
1 \times 2)\end{array}$ & $2(3 \times 0+1 \times 2)$ & $2(3 \times 0+1 \times 2)$ & $2(3 \times 0+1 \times 2)$ \\
\hline $\begin{array}{l}\mathrm{Na}_{2} \mathrm{~S} \\
(45 \mathrm{~min})\end{array}$ & $3+4(4 \times[3+4])$ & $0(4 \times 0)$ & $0(4 \times 0)$ & $0(4 \times 0)$ & $0(4 \times 0)$ \\
\hline
\end{tabular}

All animals showed normal function before aortic balloon occlusion. During reperfusion, only one animal in the sodium chloride group $(n=4)$ showed joint movement whereas all other pigs in the sodium sulfide $(n=4)$ group lost hind motor function. The data of the two groups with $30 \mathrm{~min}(n=3)$ and $40 \mathrm{~min}(n=2)$ occlusion time were obtained in preliminary experiments as described above. See text for details on the scoring system

This pig strain spontaneously develops hypothermia during anesthesia [12]. Core temperature was not externally influenced since hypothermia is an independent protective measurement possibly interfering with the effects of hydrogen sulfide [39, 40] and normothermia was not restored in order to avoid any pro-inflammatory and/or pro-apoptotic effects [41, 42].

The protective effects of compounds that release $\mathrm{H}_{2} \mathrm{~S}$ endogenously on I/R injury are controversial. In porcine models of IR injury, $\mathrm{Na}_{2} \mathrm{~S}$ exerted protective effects, such as maintaining mitochondrial function, neutralizing ROS and anti-inflammatory capacities, and reducing apoptosis especially in hearts and kidneys [5]. Administration of exogenous therapeutic $\mathrm{Na}_{2} \mathrm{~S}$ prior to the onset of reperfusion after acute myocardial ischemia reduced the apoptotic response to I/R injury in a pig model [13]. In addition, its anti-inflammatory properties improved myocardial function and coronary microvascular reactivity by reducing infarct size $[14,15]$. Ex vivo experiments of porcine kidneys, which were subjected to $25 \mathrm{~min}$ of warm ischemia and $18 \mathrm{~h}$ of cold storage under sulfide treatment, showed an improvement of renal function associated with a reduction of oxidative stress [43]. During porcine aortic occlusion-induced kidney I/R injury, pretreatment with $\mathrm{Na}_{2} \mathrm{~S}$ attenuated tissue injury and organ dysfunction as a result of reduced inflammation and oxidative and nitrosative stress [27]. Administration of $\mathrm{H}_{2} \mathrm{~S}$ in a large animal model of severe hemorrhagic shock resulted in a significant decrease in resuscitative requirements, decreased metabolic acidosis, and less end-organ histologic injury compared with standard resuscitation. On the other hand, it did not induce profound metabolic suppression as seen in rodents and appears to have alternative mechanisms of action in large animals, such as altered gene expression for hypoxia-inducible factor $1 \alpha$ (HIF $1 \alpha)$ and vascular endothelial growth factor receptor (VEGFr) [44]. In contrast, the present study showed that pretreatment with $\mathrm{Na}_{2} \mathrm{~S}$ had no protective effect on the neuronal damage after aortic balloon occlusion in pigs. It could be speculated that the neuroprotection of sodium sulfide is dose-dependent. Current evidence seems to suggest that the presence of $\mathrm{H}_{2} \mathrm{~S}$ in the ischemic brain may either be deleterious or protective depending on its concentration, deleterious when high and protective when low [45]. Deleterious actions include adversely influenced mitochondrial function, such as inhibited oxidative phosphorylation, as well as $\mathrm{N}$-methyl-D-aspartate (NMDA) receptor and calcium-mediated cell death. $\mathrm{H}_{2} \mathrm{~S}$ acts protective via its anti-inflammatory, anti-oxidative, and anti-apoptotic capacities [45]. Sulfide levels in our study were not measured because on the one hand sulfide interacts 
with numerous blood components (e.g., hemoglobin, iron, and dissolved oxygen) [46, 47]. For example, ex vivo spiking blood with defined amounts of sulfide does not allow for its quantitative recovery, so that sulfide administration in vivo may not necessarily yield detectable concentration changes unless toxic doses are used [48, 49]. In addition, it interferes with different reagents during chemical analysis, making it hard to measure accurate values. And a third point to be considered is that measured levels do not reflect the effect of the applied sulfide on the targeted cells or tissues. Different cells have different capacities to trap or oxidize sulfide. Especially cells with a high amount of metallo compounds or high expression of sulfide quinone reductase (e.g., hepatocytes or colonocytes) are immune against toxic sulfide levels whereas other cell types (e.g., cardiomyocytes or neurons) are more vulnerable $[46,47]$.

\section{Limitations of the study}

It could be argued that we did not achieve sufficiently high sulfide levels in the spinal cord tissue. After administration of $3 \mathrm{mg} / \mathrm{kg} \mathrm{NaSH}$ in rats challenged with traumatic brain injury, a significant rise of sulfide levels in brain tissue could be measured by Jiang et al. [50], suggesting that the comparable amounts in our experiment also yielded sufficient tissue sulfide levels. Nevertheless, since we did not measure tissue sulfide concentrations, we cannot exclude insufficient adsorption into the spinal cord due to different pharmacokinetics.

A balloon occlusion time of $45 \mathrm{~min}$ has probably been too long for the integrity of the spinal cord, mediating an irreversible $\mathrm{I} / \mathrm{R}$ injury. In surgical settings, a maximum of $30 \mathrm{~min}$ for the cross-clamping is needed to prevent spinal cord injury. Another major limitation of this study was the low sample size of the experimental animals. However, since there was no improvement of the neurological damage after sodium sulfide application, the experiments were stopped for ethical reasons according to the 3Rs of animal research [51].

\section{Conclusion}

In summary, in this porcine model of aortic occlusion-induced I/R injury, we demonstrated that pretreatment and continuous infusion with sodium sulfide did not protect spinal cord tissue from neuronal damage. Further studies are warranted to investigate the possible protective effects of different doses or other ways of application (e.g., inhalative), or other carriers of sulfide as sodium (e.g., chelates) on experimental models with pre-existing arteriosclerosis.

\footnotetext{
Abbreviations

CVP: Central venous pressure; eNO: Endothelial nitrogen oxide; EPO-R: Erythropoietin receptor; FBM: Familial hypercholesteremia Bretoncelles Meishan; $\mathrm{FiO}_{2}$ : Fraction of inspiratory oxygen; $\mathrm{H}_{2} \mathrm{~S}$ : Hydrogen sulfide; HE: Hematoxylin and eosin; HIF: Hypoxia-inducible factor; I/R: Ischemia/reperfusion; IQR: Interquartile range; IU: International unit; LDL: Low-density lipoprotein; MAP: Mean arterial pressure; MEP: Motor evoked potential; MOF: Multi-organ failure; MP: Measuring point; $\mathrm{NaOH}$ : Sodium hydroxide; $\mathrm{NaSH}$ : Sodium hydrogen sulfide; NMDA: N-Methyl-D-aspartate; PEEP: Positive end-expiratory pressure; ROS: Reactive oxygen species; TCFA: Thin-cap fibroatheroma; VEGFr: Vascular endothelial growth factor receptor
}

Acknowledgements

This work was supported by the German Research Foundation (DFG) within the funding program Open Access Publishing. 
Availability of data and materials

The datasets generated during and/or analyzed during the current study are available from the corresponding author on reasonable request.

\section{Authors' contributions}

FS, PR, and HS conceived the study and designed the experiment. FS and MW were responsible for the anesthesia and surgery and together with $A B$ and $K L$ for the data collection and statistical analysis. $A B, O M$, and $A S$ were responsible for the histology. $C S$ provided the intravenous formulation of hydrogen sulfide. $A B, K L$, and $M W$ drafted the manuscript. All authors read and approved the final manuscript.

\section{Ethics approval}

The experiments were performed in adherence with the National Institutes of Health Guidelines on the use of Laboratory Animals and after approval of the protocol by the regional council of Tübingen (Registration number 905).

\section{Consent for publication}

Not applicable

\section{Competing interests}

The authors declare that they have no competing interest.

\section{Publisher's Note}

Springer Nature remains neutral with regard to jurisdictional claims in published maps and institutional affiliations.

\section{Author details}

1Department of Anesthesiology, University Hospital Regensburg, Franz-Josef-Strauß-Allee 11, 93053 Regensburg, Germany. ${ }^{2}$ Institute of Anesthesiological Pathophysiology and Process Engineering, University Hospital UIm, Helmholtzstraße 8/1, 89081 Ulm, Germany. ${ }^{3}$ Department of Cardiothoracic Surgery, University Hospital Regensburg, Franz-Josef-Strauß-Allee 11, 93053 Regensburg, Germany. ${ }^{4}$ Institute of Pathology - Section Neuropathology, University Hospital Ulm, Albert-Einstein-Allee 23, 89081 Ulm, Germany. ${ }^{5}$ Department of Vascular and Endovascular Surgery, Heinrich-Heine-Universität Düsseldorf, Moorenstraße 5, 40225 Düsseldorf, Germany. ${ }^{6}$ Department of Anesthesiology, University of Texas Medical Branch, 301 University Boulevard, Galveston, TX 77555, USA.

Received: 22 June 2018 Accepted: 14 October 2018

Published online: 24 October 2018

\section{References}

1. Zammert M, Gelman S (2016) The pathophysiology of aortic cross-clamping. Best Pract Res Clin Anaesthesiol 30(3):257269. https://doi.org/10.1016/..bpa.2016.07.006

2. Alonso Pérez M, Llaneza Coto JM, Del Castro Madrazo JA et al (2017) Debranching aortic surgery. J Thorac Dis 9(Suppl 6):S465-S477. https://doi.org/10.21037/jtd.2017.03.87

3. Gelman S (1995) The pathophysiology of aortic cross-clamping and unclamping. Anesthesiology 82(4):1026-1060

4. Kimura H (2013) Physiological role of hydrogen sulfide and polysulfide in the central nervous system. Neurochem Int 63(5):492-497. https://doi.org/10.1016/j.neuint.2013.09.003

5. Guo W, J-t K, Cheng Z-y et al (2012) Hydrogen sulfide as an endogenous modulator in mitochondria and mitochondria dysfunction. Oxidative Med Cell Longev 2012:878052. https://doi.org/10.1155/2012/878052

6. Li L, H-K J, Y-p L et al (2015) Hydrogen sulfide protects spinal cord and induces autophagy via miR-30c in a rat model of spinal cord ischemia-reperfusion injury. J Biomed Sci 22:50

7. Aslami H, Schultz MJ, Juffermans NP (2009) Potential applications of hydrogen sulfide-induced suspended animation. Curr Med Chem 16(10):1295-1303

8. Wagner F, Asfar P, Calzia E et al (2009) Bench-to-bedside review: hydrogen sulfide--the third gaseous transmitter: applications for critical care. Crit Care 13(3):213. https://doi.org/10.1186/cc7700

9. Módis K, Bos EM, Calzia E et al (2014) Regulation of mitochondrial bioenergetic function by hydrogen sulfide. Part II. Pathophysiological and therapeutic aspects. Br J Pharmacol 171(8):2123-2146. https://doi.org/10.1111/bph.12368

10. Hartmann C, Nussbaum B, Calzia E et al (2017) Gaseous mediators and mitochondrial function: the future of pharmacologically induced suspended animation? Front Physiol 8:691. https://doi.org/10.3389/fphys.2017.00691

11. Thim T, Hagensen MK, Drouet $L$ et al (2010) Familial hypercholesterolaemic downsized pig with human-like coronary atherosclerosis: a model for preclinical studies. Eurolntervention 6(2):261-268

12. Matějková Š, Scheuerle A, Wagner F et al (2013) Carbamylated erythropoietin-FC fusion protein and recombinant human erythropoietin during porcine kidney ischemia/reperfusion injury. Intensive Care Med 39(3):497-510. https://doi. org/10.1007/s00134-012-2766-y

13. Sodha NR, Clements RT, Feng J et al (2008) The effects of therapeutic sulfide on myocardial apoptosis in response to ischemia-reperfusion injury. Eur J Cardiothorac Surg 33(5):906-913. https://doi.org/10.1016/j.ejcts.2008.01.047

14. Sodha NR, Clements RT, Feng J et al (2009) Hydrogen sulfide therapy attenuates the inflammatory response in a porcine model of myocardial ischemia/reperfusion injury. J Thorac Cardiovasc Surg 138(4):977-984. https://doi.org/10. 1016/j.jtcvs.2008.08.074

15. Osipov RM, Robich MP, Feng J et al (2009) Effect of hydrogen sulfide in a porcine model of myocardial ischemiareperfusion: comparison of different administration regimens and characterization of the cellular mechanisms of protection. J Cardiovasc Pharmacol 54(4):287-297. https://doi.org/10.1097/FJC.0b013e3181b2b72b

16. Kuriyama T, Latham LP, Horwitz LD et al (1984) Role of collateral ventilation in ventilation-perfusion balance. J Appl Physiol Respir Environ Exerc Physiol 56(6):1500-1506 
17. Nirmalan M, Willard TM, Edwards DJ et al (2005) Estimation of errors in determining intrathoracic blood volume using the single transpulmonary thermal dilution technique in hypovolemic shock. Anesthesiology 103(4):805-812

18. Papakostas JC, Matsagas MI, Toumpoulis IK et al (2006) Evolution of spinal cord injury in a porcine model of prolonged aortic occlusion. J Surg Res 133(2):159-166. https://doi.org/10.1016/j.jss.2005.10.007

19. Simon F, Scheuerle A, Gröger M et al (2011) Comparison of carbamylated erythropoietin-FC fusion protein and recombinant human erythropoietin during porcine aortic balloon occlusion-induced spinal cord ischemia/ reperfusion injury. Intensive Care Med 37(9):1525-1533. https://doi.org/10.1007/s00134-011-2303-4

20. Blaisdell FW, Cooley DA (1962) The mechanism of paraplegia after temporary thoracic aortic occlusion and its relationship to spinal fluid pressure. Surgery 51:351-355

21. Wadouh F, Lindemann EM, Arndt CF et al (1984) The arteria radicularis magna anterior as a decisive factor influencing spinal cord damage during aortic occlusion. J Thorac Cardiovasc Surg 88(1):1-10

22. Weigang $E$, Luehr M, von Samson P et al (2005) Development of a special balloon occlusion device to prevent adverse events in high-risk patients during open aortic surgery. Eur Surg Res 37(4):204-209. https://doi.org/10. $1159 / 000087864$

23. Maier C, Scheuerle A, Hauser B et al (2007) The selective poly(ADP)ribose-polymerase 1 inhibitor INO1001 reduces spinal cord injury during porcine aortic cross-clamping-induced ischemia/reperfusion injury. Intensive Care Med 33(5):845-850. https://doi.org/10.1007/s00134-007-0585-3

24. Meylaerts SA, de Haan P, Kalkman CJ et al (2000) Prevention of paraplegia in pigs by selective segmental artery perfusion during aortic cross-clamping. J Vasc Surg 32(1):160-170. https://doi.org/10.1067/mva.2000.107571

25. Kick J, Hauser B, Bracht $\mathrm{H}$ et al (2007) Effects of a cantaloupe melon extract/wheat gliadin biopolymer during aortic cross-clamping. Intensive Care Med 33(4):694-702. https://doi.org/10.1007/s00134-006-0518-6

26. Maharajh GS, Pascoe EA, Halliday WC et al (1996) Neurological outcome in a porcine model of descending thoracic aortic surgery. Left atrial-femoral artery bypass versus clamp/repair. Stroke 27(11):2095-2100 discussion 2101

27. Simon F, Scheuerle A, Gröger M et al (2011) Effects of intravenous sulfide during porcine aortic occlusion-induced kidney ischemia/reperfusion injury. Shock 35(2):156-163. https://doi.org/10.1097/SHK.0b013e3181f0dc91

28. Duggal N, Lach B (2002) Selective vulnerability of the lumbosacral spinal cord after cardiac arrest and hypotension. Stroke 33(1):116-121

29. Meylaerts SA, de Haan P, Kalkman CJ et al (1999) The influence of regional spinal cord hypothermia on transcranial myogenic motor-evoked potential monitoring and the efficacy of spinal cord ischemia detection. J Thorac Cardiovasc Surg 118(6):1038-1045. https://doi.org/10.1016/S0022-5223(99)70099-1

30. Simon F, Scheuerle A, Calzia E et al (2008) Erythropoietin during porcine aortic balloon occlusion-induced ischemia/ reperfusion injury. Crit Care Med 36(7):2143-2150. https://doi.org/10.1097/CCM.0b013e31817d7912

31. Bassols A, Costa C, Eckersall PD et al (2014) The pig as an animal model for human pathologies: a proteomics perspective. Proteomics Clin Appl 8(9-10):715-731. https://doi.org/10.1002/prca.201300099

32. Toghill BJ, Saratzis A, Bown MJ (2017) Abdominal aortic aneurysm-an independent disease to atherosclerosis? Cardiovasc Pathol 27:71-75. https://doi.org/10.1016/j.carpath.2017.01.008

33. van der Putten K, Braam B, Jie KE et al (2008) Mechanisms of disease: erythropoietin resistance in patients with both heart and kidney failure. Nat Clin Pract Nephrol 4(1):47-57. https://doi.org/10.1038/ncpneph0655

34. Stenvinkel P, Bárány P (2002) Anaemia, rHuEPO resistance, and cardiovascular disease in end-stage renal failure; links to inflammation and oxidative stress. Nephrol Dial Transplant 17(Suppl 5):32-37

35. Coletta C, Papapetropoulos A, Erdelyi K et al (2012) Hydrogen sulfide and nitric oxide are mutually dependent in the regulation of angiogenesis and endothelium-dependent vasorelaxation. Proc Natl Acad Sci U S A 109(23):9161-9166. https://doi.org/10.1073/pnas.1202916109

36. King AL, Polhemus DJ, Bhushan S et al (2014) Hydrogen sulfide cytoprotective signaling is endothelial nitric oxide synthase-nitric oxide dependent. Proc Natl Acad Sci U S A 111(8):3182-3187. https://doi.org/10.1073/pnas.1321871111

37. Bibli S-I, Szabo C, Chatzianastasiou A et al (2017) Hydrogen sulfide preserves endothelial nitric oxide synthase function by inhibiting proline-rich kinase 2: implications for cardiomyocyte survival and cardioprotection. Mol Pharmacol 92(6): 718-730. https://doi.org/10.1124/mol.117.109645

38. Szabo C (2017) Hydrogen sulfide, an enhancer of vascular nitric oxide signaling: mechanisms and implications. Am J Physiol Cell Physiol 312(1):C3-C15. https://doi.org/10.1152/ajpcell.00282.2016

39. Inoue S, Mori A, Shimizu H et al (2013) Combined use of an epidural cooling catheter and systemic moderate hypothermia enhances spinal cord protection against ischemic injury in rabbits. J Thorac Cardiovasc Surg 146(3):696701. https://doi.org/10.1016/j.jtcvs.2012.11.040

40. Tabayashi K, Motoyoshi N, Saiki Y et al (2008) Efficacy of perfusion cooling of the epidural space and cerebrospinal fluid drainage during repair of extent I and II thoracoabdominal aneurysm. J Cardiovasc Surg 49(6):749-755

41. Rocha-Ferreira E, Kelen D, Faulkner S et al (2017) Systemic pro-inflammatory cytokine status following therapeutic hypothermia in a piglet hypoxia-ischemia model. J Neuroinflammation 14(1):44. https:/doi.org/10.1186/s12974-017-0821-X

42. Wang B, Armstrong JS, Lee J-H et al (2015) Rewarming from therapeutic hypothermia induces cortical neuron apoptosis in a swine model of neonatal hypoxic-ischemic encephalopathy. J Cereb Blood Flow Metab 35(5):781-793. https://doi. org/10.1038/jcbfm.2014.245

43. Hosgood SA, Nicholson ML (2010) Hydrogen sulphide ameliorates ischaemia-reperfusion injury in an experimental model of non-heart-beating donor kidney transplantation. Br J Surg 97(2):202-209. https://doi.org/10.1002/bjs.6856

44. Satterly SA, Salgar S, Hoffer Z et al (2015) Hydrogen sulfide improves resuscitation via non-hibernatory mechanisms in a porcine shock model. J Surg Res 199(1):197-210. https://doi.org/10.1016/j.jss.2015.04.001

45. Chan SJ, Wong PT-H (2017) Hydrogen sulfide in stroke: protective or deleterious? Neurochem Int 105:1-10. https://doi. org/10.1016/j.neuint.2016.11.015

46. Hughes MN, Centelles MN, Moore KP (2009) Making and working with hydrogen sulfide: the chemistry and generation of hydrogen sulfide in vitro and its measurement in vivo: a review. Free Radic Biol Med 47(10):1346-1353. https://doi. org/10.1016/j.freeradbiomed.2009.09.018

47. Haouzi P (2016) Is exogenous hydrogen sulfide a relevant tool to address physiological questions on hydrogen sulfide? Respir Physiol Neurobiol 229:5-10. https://doi.org/10.1016/j.resp.2016.03.015 
48. Whitfield NL, Kreimier EL, Verdial FC et al (2008) Reappraisal of H2S/sulfide concentration in vertebrate blood and its potential significance in ischemic preconditioning and vascular signaling. Am J Physiol Regul Integr Comp Physiol 294(6):R1930-R1937. https://doi.org/10.1152/ajpregu.00025.2008

49. Furne J, Saeed A, Levitt MD (2008) Whole tissue hydrogen sulfide concentrations are orders of magnitude lower than presently accepted values. Am J Physiol Regul Integr Comp Physiol 295(5):R1479-R1485. https://doi.org/10.1152/ajpregu. 90566.2008

50. Jiang $X$, Huang $Y$, Lin W et al (2013) Protective effects of hydrogen sulfide in a rat model of traumatic brain injury via activation of mitochondrial adenosine triphosphate-sensitive potassium channels and reduction of oxidative stress. J Surg Res 184(2):e27-e35. https://doi.org/10.1016/j.jss.2013.03.067

51. Russell WMS, Burch RL (1992) The principles of humane experimental technique, Chapter 4, Special ed. UFAW, Potters Bar http://altweb.jhsph.edu/pubs/books/humane_exp/chap4d

Submit your manuscript to a SpringerOpen ${ }^{\circ}$ journal and benefit from:

- Convenient online submission

- Rigorous peer review

Open access: articles freely available online

- High visibility within the field

- Retaining the copyright to your article

Submit your next manuscript at $\boldsymbol{\nabla}$ springeropen.com 